\title{
A complicated case of recurrent Cowper's gland abscess
}

\author{
Pietro Pepe, Ludovica Pepe, Astrid Bonaccorsi, Paolo Panella, Michele Pennisi \\ Urology Unit, Cannizzaro Hospital, Catania, Italy.
}

\begin{abstract}
Summary A Caucasian man 64 years old was admitted to our department for fever, strangury, frequency and pain in the perineum secondary to the relapse of Cowper's gland abscess previously treated by antibiotic therapy and trans-perineal ultrasound-guided aspiration. At admission, the clinical parameters were suggestive of sepsis; moreover, the trans-perineal ultrasound detected an hypoechoic mass suspicious for the recurrence of Cowper's gland abscess. A suprapubic catheter was positioned and a targeted antibiotic therapy (Colistin 9000.000 U intravenously every day for 8 days plus meropenem $500 \mathrm{mg}$ intravenously every 8 hours for 10 days) was administered. The patient during the follow up presented long fibers of mucus in the urine and recurrent positive urine culture, therefore two months later underwent trans-perineal surgical asportation of the left Cowper's gland. One month after surgery the patient was readmitted for the presence of a urinary fistula between bulbar urethra and perineum.

A new suprapubic catheter was positioned and after three months was removed because a complete restitutio ad integrum was shown by retrograde cystourethrogram and uroflowmetry. In conclusion, the abscess of Cowper's gland could represent a very rare but severe clinical event that need aggressive therapy and close follow up for its potentially high rate of early and late clinical complications; in the presence of recurrence the surgical asportation of the Cowper's gland should be considered.
\end{abstract}

KEY WORDS: Cowper's gland abscess; Urinary perineum fistula; Transperineal ultrasound; Cowper's gland surgery.

Submitted 17 February 2019; Accepted 9 April 2014

\section{INTRODUCTION}

The abscess of the Cowper gland $(1,2)$ is associated with fever, malaise and severe pain in the perineum combined frequency, urgency, painful defecation and sometime acute urinary retention. We, previously, showed a case of Cowper's gland abscess complicated by sepsis treated conservatively (targeted antibiotic therapy, trans-perineal ultrasound-guided aspiration of the abscess and suprapubic catheter) with an apparent restitutio ad integrum (3). We now report the clinical evolution and relapse of the same clinical case that needed the surgical asportation of the Cowper's gland subsequently complicated by a urinary perineum fistula.

\section{Case report}

A Caucasian man 64 years old was readmitted to our hospital for the presence of fever $\left(40^{\circ} \mathrm{C}\right)$, strangury, frequency, pain in the perineum and long fibers of mucus in the urine. The patient had been treated with three cycles of antibiotics during hospitalization about nine months before for the presence of sepsis secondary to an abscess of the left Cowper's gland; in addition, for the persistence of symptoms, a culture of trans-perineal ultrasound-guided aspiration of Cowper's gland abscess showed the presence of Pseudomonas Aeruginosa sensitive to ciprofloxacin. A suprapubic catheter was positioned and antibiotic therapy (oral ciprofloxacin $1000 \mathrm{mg}$ per day) was administrated for 4 weeks with apparent restitutio ad integrum (urine and urethral swab cultures were negative) and absence of clinical symptoms for the following three months from hospital discharge (3).

At last hospital readmission, PSA was $1.8 \mathrm{ng} / \mathrm{ml}$, kidney and bladder ultrasound were normal (absence of postvoid urinary residual); urological examination was characterized by normal prostate, penis and testicular findings with pain and skin redness in correspondence of the perineum. The trans-perineal ultrasound detected a hypoechoic mass suggestive for the relapse of the left Cowper's gland abscess that was confirmed by pelvic magnetic resonance imaging. A suprapubic catheter was positioned; blood culture found presence of Escherichia coli and the patient underwent targeted antibiotic therapy (Colistin 9000.000 U intravenously every day for 8 days plus Meropenem 500 mg intravenously every 8 hours for 10 days) according to antibiogram results; seven days from the end of the therapy and in the absence of urinary symptoms the patient underwent 3 blood culture (negative), urine culture (negative), serum pro-calcitonin (negative) and was discharged from the hospital.

The patient during the follow up presented again long fibers of mucus in the urine and recurrent positive urine cultures, therefore two months later underwent transperineal surgical asportation of the left Cowper's gland. After the incision of perineum the gland was identified during surgery by metilene blue dye that was previously injected trans-perineally under transrectal ultrasound guidance; the Cowper's gland was removed and the duct between the gland and the bulbar urethra was identified and closed in correspondence of the urethra (Figure 1). The transcutaneous drain was removed after four days and the patient was discharged after two weeks from surgery; two weeks later the urethral and suprapubic catheters were removed. Definitive histological specimen showed an abscess of the Cowper's gland. One month from surgery the patient was readmitted again for the presence of a urinary fistula between bulbar urethra and 
Figure 1.

Left Cowper's gland (a) was removed by transperineal surgical approach (b).

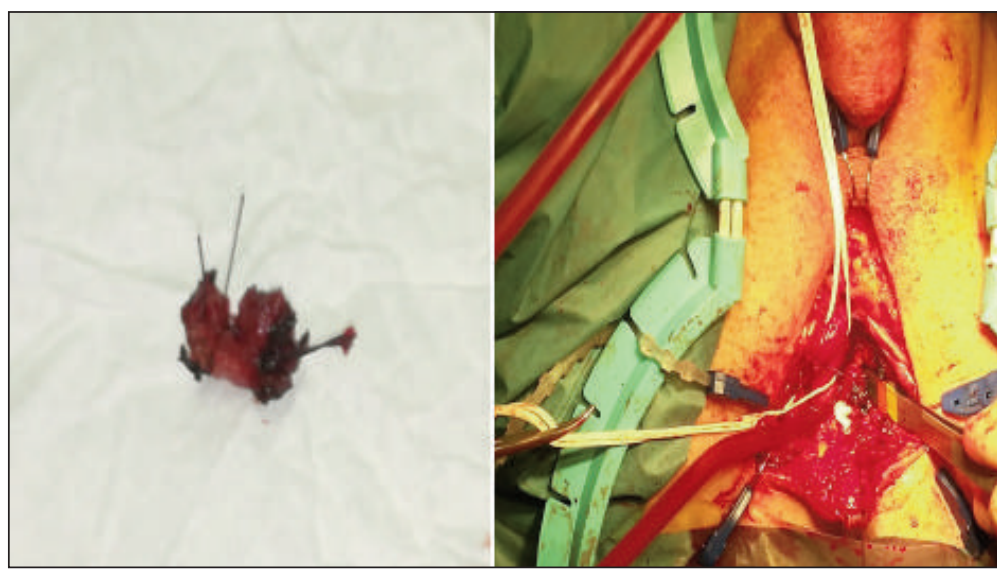

Figure 2.

Transperineal ultrasound during urethral echography (saline solution injected through the urethra). In the correspondence of the spongiosum corpus is clearly showed a large hypoechoic zone (arrow) secondary to a cutaneous fistula between bulbar urethra and perineum.

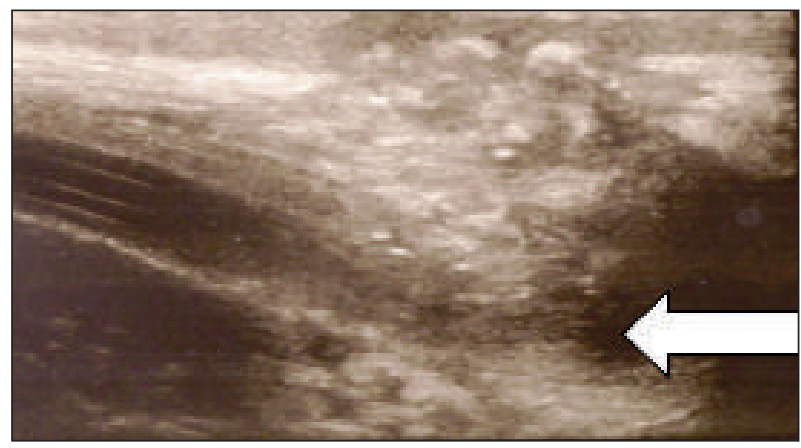

perineum (Figure 2). A new suprapubic catheter was positioned and after three months was removed after complete restitutio ad integrum was showed (absence of fistula or urethral stenosis) by retrograde cystourethrogram and uroflowmetry.

\section{Discussion}

Cowper's gland abscess has been rarely reported $(1,2)$ but it should be considered in any male presenting with long persistent irritative or obstructive symptoms following many cycles of antibiotic therapy. Cowper's gland defect (i.e. syringocele) could be a focal point for bacterial persistence in the urinary tract following acute prostatitis (4-7).

The treatment is appropriate antibiotic therapy, but in the presence of abscess direct aspiration is the most efficacious procedure; when underestimated, Cowper's gland abscess could induce a perineal fistula (8). In the clinical case previously showed, to our knowledge the first reported in literature, we observed multiple acute recurrences requiring removal of the Cowper's gland that was also complicated by a urinary fistula between bulbar urethra and perineum.

\section{Conclusions}

The abscess of Cowper's gland could represent a very severe clinical event that need aggressive therapy and close follow up for its potentially high rate of early and late clinical complications; in the presence of relapse the surgical asportation of the Cowper's gland should be considered.

\section{REFERENCES}

1. Chwallar R. Cowperitis: a rarely diagnosed frequent disease, its diagnosis and treatment. Zeitschrift Fur Urologie. 1963; 56:155-166.

2. Martínez-Sagarra JM, Cuervo J, Cortiñas JR. Cowperitis. Actas Urológicas Españolas. 1981; 5:255-258

3. Pepe P, Pepe L, Bonaccorsi A, et al. Sepsis secondary to Cowper's gland abscess. Urol Case Rep. 2017; 15:48-49.

4. Lo A, Upadhyay V, Teele RL. Syringocoele of the bulbourethral duct with additional lower genito-urinary anomalies. Pediatric Radiolology. 2011; 41:1201-1204.

5. Blasl F, Rösch WH, Koen M, et al. Cowper's syringocele: A rare differential diagnosis of infravesical obstruction in boys and young adults. J Pediatr Urol. 2017; 13:52.e1-52.e5.

6. Arena S, Scuderi MG, Arena F, Di Benedetto V. Management of "open" syringocele based on urodynamic findings. Pediatr Med Chir. 2008; 30:35-40

7. Maizels M, Stephens FD, King LR, Firlit CF. Cowper's syringocele: a classification of dilatations of Cowper's gland duct based upon clinical characteristics of 8 boys. J Urol. 1983; 129:111-114.

8. Birnstingl J, Griffiths D, Nicol CS, Redmond A. Two cases of perineal fistula following cowperitis. Br J Vener Dis. 1957; 33:246-248.

\section{Correspondence}

Pietro Pepe, MD (Corresponding Author) piepepe@hotmail.com

Ludovica Pepe, MD

Astrid Bonaccorsi, MD

Paolo Panella, MD

Michele Pennisi, MD

Urology Unit - Cannizzaro Hospital

Via Messina 829, Catania (Italy) 